\title{
Oxidation of PAHs in water solution by ozone combined with ultraviolet radiation
}

\author{
Stanisław Ledakowicz, Jacek S. Miller, ${ }^{\dagger}$ and Dorota Olejnik \\ Faculty of Process and Environmental Engineering, Technical University of Łódź, \\ ul. Wólczańska 213, 90-924 Łódź, Poland
}

\begin{abstract}
The oxidation of three polycyclic aromatic hydrocarbons (PAHs): benzo[a]pyrene (BAP), chrysene $(\mathrm{CHR})$ and fluorene (FLU) in aqueous solution using ozone assisted by UV radiation was investigated. The influence of $\mathrm{pH}$ of the reaction mixture, ozone concentration and the presence of a radical scavenger on the reaction rate was determined. The highest rate of PAHs disappearance was achieved in acidic solutions. The radical scavenger-tert-butanol, effectively inhibited the rate of BAP and CHR destruction but had a slight influence in the case of FLU. The rate constants of direct reaction of PAHs with ozone were calculated using our earlier investigations and they were equal to $6.8 \times 10^{4} ; 6.9 \times 10^{3}$ and $62 \mathrm{M}^{-1} \mathrm{~s}^{-1}$ for BAP, CHR and FLU, respectively. The contributions of direct ozonolysis, photolysis and radical reaction to PAHs oxidation in $\mathrm{O}_{3} / \mathrm{UV}$ system were evaluated.
\end{abstract}

\section{INTRODUCTION}

Many water contaminants can be removed successfully from the aqueous phase by direct oxidation with ozone molecules in accordance with the classical or modified Criegee mechanism [1, 2]. On the other hand, the traditional ozonation process may not be effective in oxidising certain pollutants which react slowly toward ozone. For these cases, the destruction rate may be enhanced by the addition of catalysts, a second oxidant, and/or ultraviolet radiation and others. The advanced oxidation processes (AOPs) utilise indirect oxidation via on site generation of hydroxyl radicals and subsequent radical reactions as one of the possible mechanisms for pollutant destruction in the aqueous phase. Among the AOPs the combination of ozone and UV radiation deserves special consideration because of its possibilities. In this system up to three pathways of organic compound removal can develop: direct photolysis, direct ozonation and radical oxidation. The hydroxyl radicals result from the decomposition of ozone due to photolysis and a reaction with hydroxyl anion which produces hydroxyl radicals in subsequent reactions. The - $\mathrm{OH}$ radicals react without selectivity on numerous organic chemicals in water [3]. The further reaction course is more complicated as primary products compete for ozone, hydroxyl radicals and UV radiation with the target compound. Organic molecules excited by UV radiation can react with oxygen [4] and ozone [5]. Additionally, intermediates can decompose giving radical species which can take part in the reaction. Oxygen, usually delivered to the reaction mixture with ozone, is also suspected of participation in the oxidation process $[4,6]$.

The $\mathrm{O}_{3} / \mathrm{UV}$ system was successfully applied in the degradation of various substances: chlorinated

\footnotetext{
† E-mail: miller@wipos.p.lodz.pl
}

organics, nitro-compounds, aromatics, detergents and pesticides [7, 8]. Polycyclic aromatic hydrocarbons (PAHs) were also the subject of the study [9-11], but despite the importance of such investigation the literature is scarce.

PAHs constitute an important, hazardous group of priority micropollutants. Some of these compounds demonstrate mutagenic, teratogenic and carcinogenic activity [12]. They were found in the atmosphere, water, soil as well as plants and animals. Their presence was detected even in drinking water [13]. Classical methods of water purification are ineffective due to very low solubility of PAHs in water. Only AOPs can decompose them to some extent leaving sometimes toxic products. It seems that advanced oxidation processes combined with biological treatment are the most promising methods of PAHs elimination from water environment.

Experiments of ozonation and various AOPs treatment of phenanthrene in aqueous solutions show that oxidation proceeds mostly with molecular ozone at neutral pH [9]. The application of UV radiation does not improve the ozonation process efficiency.

The results of AOPs of anthracene, phenanthrene and pyrene were used for a simultaneous calculation of the quantum yields and the rate constants of direct ozonation and hydroxyl radical reaction, basing on the model which consisted of 31 elementary reactions [10]. The rate constants obtained for ozone reaction were close to $1 \times 10^{5} \mathrm{M}^{-1} \mathrm{~s}^{-1}$ and for hydroxyl radical reactions were one or two orders of magnitude higher.

The degradation of FLU, phenanthrene, and acenaphthene applying $\mathrm{O}_{3} / \mathrm{UV}$ was studied by Beltran et al. [11]. The influence, among others, of the presence of hydroxyl radicals inhibitors and $\mathrm{pH}$ of the reaction solution was investigated. The most important pathways for PAHs oxidation, except for FLU, are the direct ozonation and photolysis. The combination of ozone with UV ra- 
diation leads to a slight increase of the oxidation rate of PAHs compared to the results obtained from the ozonation or photolysis alone. This rate increase in the case of phenanthrene and acenaphthene was due to the additive contribution to ozonation and photolysis rather than to the action of hydroxyl radicals generated by a synergistic effect of both $\mathrm{O}_{3}$ and UV radiation. However, hydroxyl radical reaction is the main pathway for the oxidation of FLU [11].

The aim of the present work was to study the possibility of benzo[a]pyrene (BAP), chrysene (CHR) and fluorene (FLU) degradation in the aqueous solution under UV radiation in the presence of ozone and the influence of various parameters on the rate of their disappearance. On the basis of our earlier works [6] the contributions of direct ozonolysis, photolysis and radical reaction to PAHs oxidation in the $\mathrm{O}_{3} / \mathrm{UV}$ system were evaluated. The rate constants of direct ozonolysis were also calculated.

\section{EXPERIMENTAL}

The experiments were carried out in a $1 \mathrm{dm}^{3}$ glass reactor, immersed in a thermostatic bath to keep constant the temperature set at $20^{\circ} \mathrm{C}$ within $\pm 0.5^{\circ} \mathrm{C}$. Agitation of the reaction mixture was provided by a magnetic stirrer working at $600 \mathrm{rpm}$. The reactor was additionally equipped with a porous plate to deliver ozone gas into the reaction solution. The photoreactor was operated in a semibatch mode. During the experiments samples were collected regularly for analysis.

The study was carried out for three selected compounds: benzo[a]pyrene (98\%, Sigma), chrysene (95\%, Fluka) and fluorene (Sigma) without additional purification. Their structures are shown in Figure 1. Stock solutions were prepared in ethanol (p.a., 96\%, Polmos). Reaction solutions were prepared by introducing a proper volume of ethanol solution (usually tens of $\mu \mathrm{l}$ ) into distilled water treated in a Millipore Milli-Q Plus System. The $\mathrm{pH}$ of the reaction mixture was adjusted by adding an exact volume of natrium hydroxide (P.Ch. Lublin) or phosphoric acid (P.Ch. Lublin) solutions. As a radical scavenger tert-butyl alcohol (p.a., Fluka) was used. Ozone was generated from pure oxygen in the ozonator (made in Lublin Technical University, Poland). The samples of reaction solution were diluted with methanol (HPLC reagent, Baker Analysed), so the solvent composition was 50/50 vol. water/methanol. The addition of methanol stabilised the samples preventing PAHs deposition onto flask walls and stopped the reaction run which destroyed the remaining ozone.

A low-pressure mercury lamp TNN 15/32 (Heraeus, Hanau) emitting mainly (80\%) monochromatic radiation at $254 \mathrm{~nm}$ with the electrical power input of $15 \mathrm{~W}$ was applied. Actinometry experiments were conducted using uranyl oxalate and potassium ferric ox-

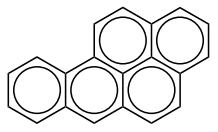

Benzo[a]pyrene

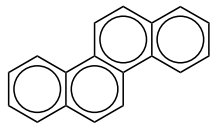

Chrysene

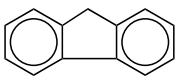

Fluorene
Figure 1. Molecular structure of investigated PAHs.

alate [14]. The reaction solution was irradiated with the intensity of $2.49 \times 10^{18}$ quanta $\mathrm{s}^{-1} \mathrm{dm}^{-3}(4.13 \times$ $10^{-6}$ einstein $\mathrm{dm}^{-3} \mathrm{~s}^{-1}$ ).

The ozone liquid phase volumetric mass transfer coefficient $\left(k_{\mathrm{L}} a\right)$ for the used reactor was determined by a dynamic method [15], measuring the oxygen concentration during saturation of the free-oxygen water. The values of $k_{\mathrm{L}} a$ for various oxygen flow rates were recalculated for ozone. The dependence of ozone volumetric mass transfer coefficient on gas flow rate is expressed by the following equation: $\left(k_{\mathrm{L}} a\right)_{\mathrm{O}_{3}}\left[\mathrm{~s}^{-1}\right]=1.11 \times$ $10^{-4} Q_{\mathrm{v}}\left[\mathrm{dm}^{3} / \mathrm{h}\right]$. The estimated interfacial area $(a)$ does not exceed $7 \mathrm{~m}^{2} / \mathrm{m}^{3}$. These values were used to verify the regime of ozone absorption [16] for selected reaction conditions.

The decay of PAHs in the reaction mixture was traced by fluorimetry using emission and synchronous spectra [17] obtained from Perkin Elmer LS50B spectrofluorimeter. The measurements were made in a $1 \mathrm{~cm}$ quartz cuvette. From time to time the PAHs content in samples was checked by liquid chromatography using Knauer HPLC apparatus with a fluorescence detector. The chromatograph was equipped with Nukleosil $100 \mathrm{C} 18 \mathrm{col}-$ umn and the mobile phase was the $80 / 20$ vol. mixture of acetonitrile/water. The ozone concentration in the gas stream was measured by BMT 963 Vent ozone analyser and in water was determined by the indigo method [18] using Unicam type 340 UV-VIS spectrophotometer.

\section{RESULTS AND DISCUSSION}

3.1. The influence of parameters. In the preliminary study it was found that the PAHs degradation rates were very high, and it was difficult to sample the reaction mixture during the reaction run. The intensity of the lamp and PAHs concentrations in water were settled, so in this circumstances only the reaction rate could be regulated by varying ozone concentration, i.e. for this heterogeneous reaction, gas flow rate and ozone content in the gas stream could be changed. But when the quantity of ozone feeding into reactor was too low, the gas leaving reactor did not contain measurable amounts of ozone and in the process course in the presence of radical scavenger an induction period was observed. This situation could suggest that the reaction developed in the fast kinetic regime of absorption. This means that rates of chemical reactions were higher 
than the maximum physical ozone absorption rate and proper arrangements for kinetic investigation could not be fulfilled. The suitable conditions were achieved at ozone dose rate $3 \times 10^{-7} ; 8 \times 10^{-7}$ and $2 \times 10^{-6} \mathrm{~mol} / \mathrm{s}$ at gas flow rates 9,8 and $25 \mathrm{dm}^{3} / \mathrm{h}$ for BAP, CHR and FLU, respectively. The evolution of relative BAP concentration during reaction for various flow rates of ozone gas is shown in Figure 2.

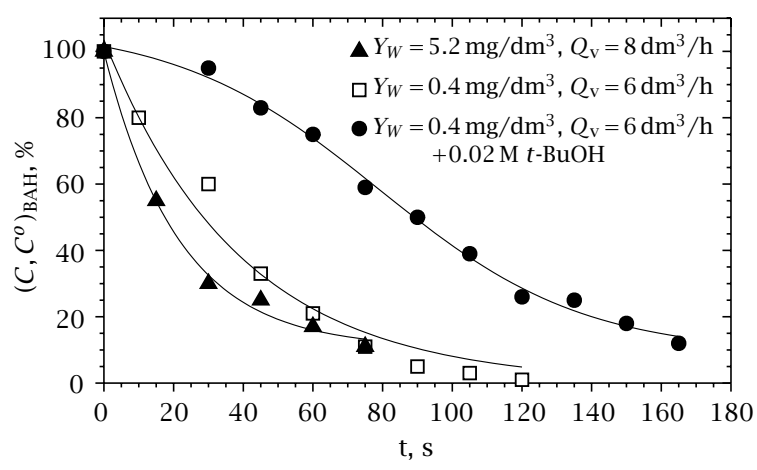

Figure 2. Variation of relative BAP concentration versus time for various ozone flow rates. $C^{o}=4.76 \times 10^{-9} \mathrm{M}$; $\mathrm{pH}=7$.

Changes in acidity and alkalinity of the reaction medium play a key role in PAHs degradation using $\mathrm{O}_{3} / \mathrm{UV}$ system, because the rates of photolysis [6], ozone solubility and its life time [19] and the rate of radical reactions [20] clearly depend on $\mathrm{pH}$. The process of PAHs decomposition was studied at five $\mathrm{pH}$ values: 2,4 , 7,9 and 12. During the reactions the changes of $\mathrm{pH}$ were not observed, probably due to very low concentrations of acidic products. Figure 3 presents the evolution of CHR and ozone concentration versus time for various $\mathrm{pH}$ values. Similar changes of substrate concentrations were observed for FLU and BAP. Ozone concentration increased up to the saturation state, which depended on the $\mathrm{pH}$. The highest values of ozone concentration, close to $1 \times 10^{-4} \mathrm{M}$, were achieved in the acidic solution, independently of the type of degraded PAH. The rate of saturation was inversely proportional to the $\mathrm{pH}$ of the reaction mixture. This observation is obvious, considering the decreasing $\mathrm{O}_{3}$ durability, while the $\mathrm{pH}$ is elevated [19]. Also the rate of PAHs disappearance decreased as the $\mathrm{pH}$ increased, especially for BAP and $\mathrm{CHR}$, which is additionally shown in Figure 4.

The reaction rate was calculated in the initial period by differentiation of the PAHs decay curve which fitted $C_{\mathrm{PAH}}, t$ experimental points. For FLU the rates for various $\mathrm{pH}$ differed insignificantly (note the scale in Figure 4). The highest rate of ozone absorption at $\mathrm{pH} 2$ seemed to be the accelerating factor for the rates of PAHs degradation through direct ozonolysis.

Figure 3 shows also, by example of CHR, that the
PAHs degradation occurs in the period when any stationary ozone concentration cannot be assumed. So, in the kinetic study the ozone concentration should be directly measured. Considering CHR degradation it is worth mentioning that its extinction coefficient varies with $\mathrm{pH}$ and the highest value is attained in the acidic environment [6], which influences the CHR decay rates through photolysis at $\mathrm{pH}=2$.

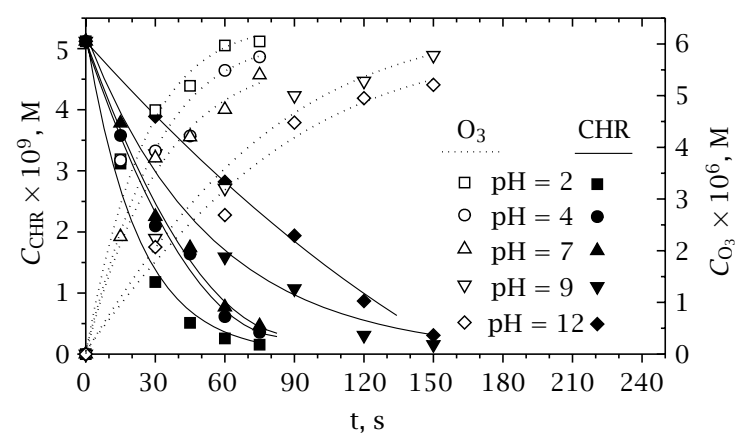

Figure 3. Evolution of CHR and ozone concentrations during oxidation at various $\mathrm{pH}$ of the reaction mixture. $C_{\mathrm{CHR}}=$ $5.12 \times 10^{-9} \mathrm{M} ; Y_{W}=15.2 \mathrm{mg} / \mathrm{dm}^{3} ; Q_{\mathrm{v}}=9 \mathrm{dm}^{3} / \mathrm{h}$.

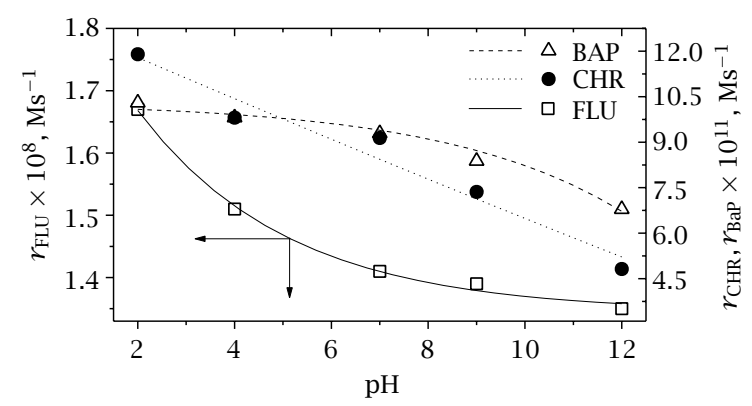

Figure 4. Dependence of PAHs degradation rate on $\mathrm{pH}$ of the reaction solution. BAP: $C^{o}=4.76 \times 10^{-9} M, Y_{W}=$ $5.2 \mathrm{mg} / \mathrm{dm}^{3}, Q_{\mathrm{v}}=8 \mathrm{dm}^{3} / \mathrm{h} ; \mathrm{CHR}: \mathrm{C}^{o}=5.12 \times 10^{-9} \mathrm{M}$, $Y_{W}=15.2 \mathrm{mg} / \mathrm{dm}^{3}, Q_{\mathrm{V}}=9 \mathrm{dm}^{3} / \mathrm{h} ; \mathrm{FLU}: \mathrm{C}^{o}=5.42 \times$ $10^{-6} \mathrm{M}, Y_{W}=30.2 \mathrm{mg} / \mathrm{dm}^{3}, Q_{\mathrm{V}}=25 \mathrm{dm}^{3} / \mathrm{h}$.

The radical pathway of PAHs degradation can be restricted by the addition of hydroxyl radical scavenger, for instance tert-butyl alcohol ( $t$-BuOH) [21]. The rate constant of its reaction with ozone is very low $\left(3 \times 10^{-3} \mathrm{M}^{-1} \mathrm{~s}^{-1}\right.$ [21]), while with $\cdot \mathrm{OH}$ radicals equals to $5.9 \times 10^{8} \mathrm{M}^{-1} \mathrm{~s}^{-1}$ [21]. Using in our experiments the $t$ - $\mathrm{BuOH}$ concentration $0.02 \mathrm{M}$, the rate of its reaction with hydroxyl radical is from $10^{3}$ to $10^{5}$ times higher than PAHs reaction with ${ }^{\circ} \mathrm{OH}$. But the reactivity of radicals formed from $t$ - $\mathrm{BuOH}$ towards PAHs is questionable. For all investigated PAHs the presence of $t$ - $\mathrm{BuOH}$ clearly inhibited the reaction rate in the whole range of studied $\mathrm{pH}$. Figure 5 illustrated this observation for BAP and CHR. In the case of FLU the $t$ - $\mathrm{BuOH}$ retarded the reaction to 


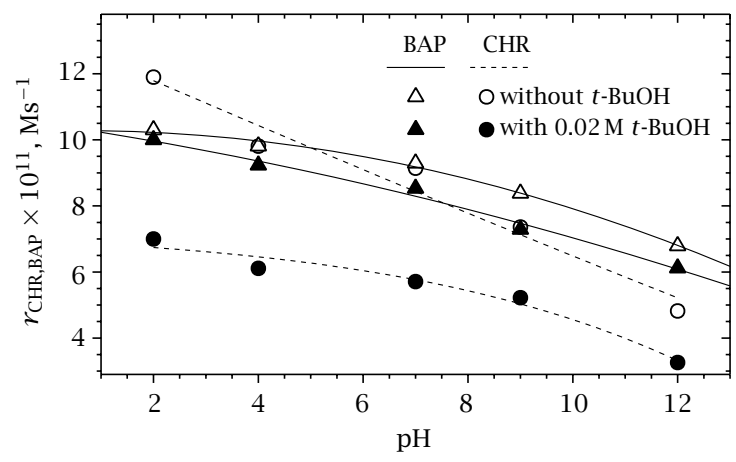

Figure 5. Comparison of BAP and CHR degradation rate in and without the presence of $t-\mathrm{BuOH}$ for various $\mathrm{pH}$ of the reaction solutions. Conditions as in Figure 4.

a small extent. This could suggest that FLU degradation occurs mainly through non radical pathway.

3.2. The kinetic study. The degradation of PAHs using $\mathrm{O}_{3} / \mathrm{UV}$ system was investigated with the goal to determine the rate constants of direct ozone reaction and to evaluate the contribution of possible pathways consuming PAHs in the whole process. The oxidation of organic compounds with ozone combined with UV radiation is a typical process belonging to AOPs. It consists of the reaction of direct photolysis, ozonolysis and hydroxyl radical reactions.

Ozone in the aqueous solution undergoes UV radiation giving oxygen atom which reacts with water to hydrogen peroxide [3]:

$$
\begin{aligned}
& \mathrm{O}_{3}+h v \longrightarrow \mathrm{O}_{2}+\mathrm{O}\left({ }^{1} \mathrm{D}\right), \\
& \mathrm{O}\left({ }^{1} \mathrm{D}\right)+\mathrm{H}_{2} \mathrm{O} \longrightarrow \mathrm{H}_{2} \mathrm{O}_{2} .
\end{aligned}
$$

Hydrogen peroxide photolyses to hydroxyl radicals:

$$
\mathrm{H}_{2} \mathrm{O}_{2}+h v \longrightarrow 2 \cdot \mathrm{OH}
$$

or dissociates to hydroperoxide anion:

$$
\mathrm{H}_{2} \mathrm{O}_{2} \rightleftarrows \mathrm{HO}_{2}^{-}+\mathrm{H}^{+} \text {. }
$$

Reactions (2) and (3) are of minor importance since UV absorption coefficient of hydrogen peroxide is small [22] and the rate constant of $\mathrm{H}_{2} \mathrm{O}_{2}$ dissociation is low [23]. The ionic form of hydrogen peroxide arises also in the reaction of ozone with hydroxyl anion:

$$
\mathrm{O}_{3}+\mathrm{OH}^{-} \longrightarrow \mathrm{HO}_{2}^{-}+\mathrm{O}_{2} .
$$

Hydroperoxide anion, in turn, reacts with ozone giving hydroperoxide radical and ozonide radical anion:

$$
\mathrm{O}_{3}+\mathrm{HO}_{2}^{-} \longrightarrow \mathrm{HO}_{2}^{\bullet}+\mathrm{O}_{3}^{\bullet-}
$$

which in subsequent reactions, shown on the scheme, forms hydroxyl radicals:

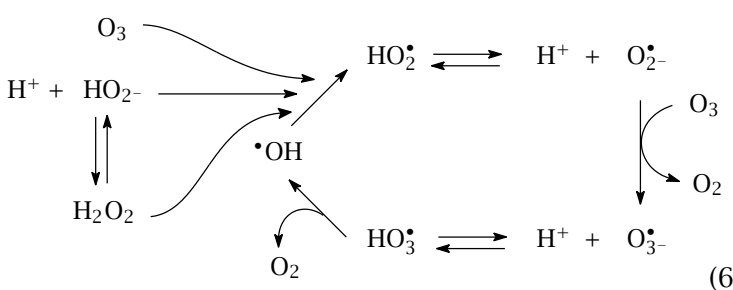

Very reactive hydroxyl radicals can attack ozone and hydrogen peroxide reproducing initiators of the cycle: hydroperoxide radicals and superoxide radical anion, according to scheme (6).

When PAHs are introduced in this system, they can undergo oxidation in three ways:

$$
\mathrm{PAH}+\left|\begin{array}{c}
\mathrm{O}_{3} \\
h v \\
\cdot \mathrm{OH}
\end{array}\right| \longrightarrow \text { products. }
$$

According to reactions (7) the rate of PAHs decay can be described by the following equation:

$$
\begin{aligned}
r=-\frac{d C_{\mathrm{PAH}}}{d t}= & \varphi_{\mathrm{PAH}} F_{\mathrm{PAH}} I_{\mathrm{a}}+k_{\mathrm{O}_{3}} C_{\mathrm{PAH}} C_{\mathrm{O}_{3}} \\
& +k_{\mathrm{OH}} C_{\mathrm{PAH}} C_{\mathrm{OH}} .
\end{aligned}
$$

For reactions carried out at low $\mathrm{pH}$ and in the presence of hydroxyl radical scavenger the radical reaction is strongly inhibited. Additionally, in the initial period of the process the reactions of intermediates can be neglected. In these circumstances in equation (8) the last right-hand element can be disregarded. Knowing the parameters of direct PAHs photolysis from our earlier work [6], the rate constants of direct ozonation can be determined. Figure 6 shows the graph of the relationship:

$$
r^{o}-\varphi_{\mathrm{PAH}} F_{\mathrm{PAH}} I_{\mathrm{a}}=f\left(C_{\mathrm{PAH}} C_{\mathrm{O}_{3}}\right),
$$

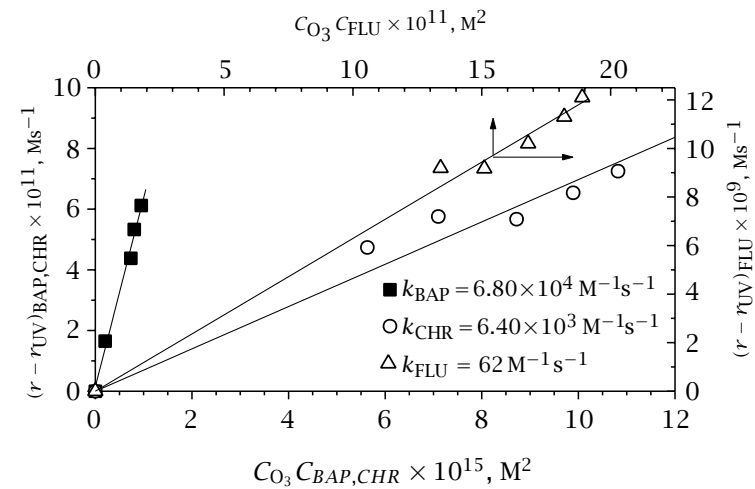

Figure 6. Determination of the rate constants of direct ozonolysis for studied PAHs. Conditions as in Figure 4 and $\mathrm{pH}=2$ with $0.02 \mathrm{Mt}$-BuOH . 
Table 1. The contributions of direct ozonolysis, photolysis and radical reaction to the oxidation with ozone combined with UV radiation.

\begin{tabular}{|c|c|c|c|c|c|}
\hline $\mathrm{pH}$ & $r^{o} \times 10^{10}, \mathrm{Ms}^{-1}$ & $\gamma_{U V}[6] \%$ & $\gamma_{\mathrm{O}_{3}} \%$ & $\gamma_{\mathrm{OH}} \%$ & $C_{\mathrm{OH}} \times 10^{13}, \mathrm{M}$ \\
\hline \multicolumn{6}{|c|}{ Benzo[a]pyrene, $t=15 \mathrm{~s} ; k_{\mathrm{OH}}=2.53 \times 10^{10} \mathrm{M}^{-1} \mathrm{~s}^{-1}[20]$} \\
\hline $2^{*}$ & 1.000 & 35.5 & 64.2 & 0.3 & 0.04 \\
\hline 2 & 1.040 & 44.3 & 41.2 & 14.5 & 2.7 \\
\hline 4 & 0.974 & 59.5 & 33.1 & 7.4 & 1.1 \\
\hline 7 & 0.930 & 74.9 & 24.6 & 0.5 & 0.06 \\
\hline 9 & 0.838 & 78.5 & 20.9 & 0.6 & 0.06 \\
\hline 12 & 0.679 & 87.9 & 7.4 & 4.7 & 0.37 \\
\hline \multicolumn{6}{|c|}{ Chrysene, $t=15 \mathrm{~s} ; k_{\mathrm{OH}}=9.82 \times 10^{9} \mathrm{M}^{-1} \mathrm{~s}^{-1}[20]$} \\
\hline $2^{*}$ & 7.000 & 18.0 & 81.9 & 0.1 & 0.13 \\
\hline 2 & 1.190 & 55.6 & 43.4 & 1.0 & 0.47 \\
\hline 4 & 0.981 & 50.8 & 10.9 & 38.3 & 12.0 \\
\hline 7 & 0.914 & 34.4 & 7.9 & 57.7 & 15.0 \\
\hline 9 & 0.736 & 29.4 & 7.6 & 63.0 & 12.0 \\
\hline 12 & 0.482 & 46.3 & 6.0 & 47.7 & 5.3 \\
\hline \multicolumn{6}{|c|}{ Fluorene, $t=120 \mathrm{~s} ; k_{\mathrm{OH}}=2.77 \times 10^{9} \mathrm{M}^{-1} \mathrm{~s}^{-1}[20]$} \\
\hline $2 *$ & 141 & 14.4 & 85.6 & $\sim 0$ & 0.01 \\
\hline 2 & 167 & 11.7 & 85.9 & 2.4 & 0.52 \\
\hline 4 & 151 & 15.8 & 58.7 & 25.5 & 5.4 \\
\hline 7 & 141 & 21.1 & 56.0 & 22.9 & 4.0 \\
\hline 9 & 140 & 25.0 & 42.6 & 32.4 & 5.4 \\
\hline 12 & 140 & 28.4 & 37.1 & 34.5 & 5.3 \\
\hline
\end{tabular}

* with $t$-BuOH $0.02 \mathrm{M}$.

$T=293 \mathrm{~K} ; I_{O}=4.13 \times 10^{-6}$ einstein $\mathrm{dm}^{-3} \mathrm{~s}^{-1}$;

BAP: $C^{o}=4.76 \times 10^{-9} \mathrm{M} ; Y_{W}=5.2 \mathrm{mg} / \mathrm{dm}^{3} ; Q_{\mathrm{v}}=8 \mathrm{dm}^{3} / \mathrm{h}$;

CHR: $C^{o}=5.12 \times 10^{-9} \mathrm{M} ; Y_{W}=15.2 \mathrm{mg} / \mathrm{dm}^{3} ; Q_{\mathrm{V}}=9 \mathrm{dm}^{3} / \mathrm{h}$;

FLU: $C^{o}=5.42 \times 10^{-6} \mathrm{M} ; Y_{W}=30.2 \mathrm{mg} / \mathrm{dm}^{3} ; Q_{\mathrm{v}}=25 \mathrm{dm}^{3} / \mathrm{h}$.

where the slope of the straight line equals to rate constant $k_{\mathrm{O}_{3}}$. The highest values were obtained for BAP $6.8 \times 10^{4} \mathrm{M}^{-1} \mathrm{~s}^{-1}$ and the smallest ones for FLU $62 \mathrm{M}^{-1} \mathrm{~s}^{-1}$. These values are a little higher than the literature data, determined for "pure" ozonolysis, $6.2 \times 10^{4} \mathrm{M}^{-1} \mathrm{~s}^{-1}$ for BAP [24] and $29 \mathrm{M}^{-1} \mathrm{~s}^{-1}$ for FLU [11]. The rate constant of CHR ozonolysis equals to $6.9 \times 10^{3} \mathrm{M}^{-1} \mathrm{~s}^{-1}$ and to our knowledge, has been determined for the first time.

In the degradation of micropollutants using AOPs a competition between possible mechanisms of oxidation usually takes place. An estimation of the importance of the individual mechanisms can help to form a picture of the process and facilitate decisions concerning the applicability of a given AOP. The contributions of particular reactions (equation (7)) in PAHs degradation in the $\mathrm{O}_{3} / \mathrm{UV}$ system were calculated according to the following formulas:

$$
\begin{aligned}
& \gamma_{\mathrm{O}_{3}}=\frac{k_{\mathrm{O}_{3}} C_{\mathrm{PAH}} C_{\mathrm{O}_{3}}}{r^{o}} 100 \%, \\
& \gamma_{\mathrm{UV}}=\frac{\varphi_{\mathrm{PAH}} F_{\mathrm{PAH}} I_{\mathrm{a}}}{r^{o}} 100 \%, \\
& \gamma_{\mathrm{OH}}=100-\gamma_{\mathrm{O}_{3}}-\gamma_{\mathrm{UV}} .
\end{aligned}
$$

The results of the calculations are shown in Table 1. The direct ozonolysis is the main degradation reaction of all investigated PAHs at $\mathrm{pH}=2$. In these conditions radical reactions are less important, and in the presence of $t$ - $\mathrm{BuOH}$ they can be neglected, which confirms our assumption and simplification in $k_{\mathrm{O}_{3}}$ determination. As the $\mathrm{pH}$ of the reaction solution increases the participation of ozonolysis falls down, according to expectations. However, for FLU this decrease is not so large, at $\mathrm{pH}=12$ ozonolysis share $37 \%$ in the whole degradation. The data presented by Beltran et al. [11] are inconsistent with our results of FLU decomposition.

The contribution of photolysis for all PAHs increases as the $\mathrm{pH}$ is growing. Interesting appears to be the participation of radical reactions upon $\mathrm{pH}$ for particular $\mathrm{PAH}$. Its contribution in FLU degradation increases as the $\mathrm{pH}$ increases; for CHR it increases up to $\mathrm{pH}=9$ and then decreases; for BAP it falls down to $\mathrm{pH}=7$ and then slowly grows.

From the practical point of view, because most of natural waters is neutral, it is important to note that a dominating degradation reaction at $\mathrm{pH}=7$ for BAP is photolysis, for CHR-reaction with hydroxyl radicals and for FLU-ozonolysis. Recapitulating, the kind of ox- 
idation pathway varies depending on the nature of the starting PAH.

The contribution of radical reaction allowed the hydroxyl radical concentration to be estimated. Using literature value of the rate constant for PAHs reaction with ${ }^{\bullet} \mathrm{OH}$ radicals [20] the calculations were done according to the formula:

$$
C_{\mathrm{OH}}=\frac{r^{o} \gamma_{\mathrm{OH}}}{100 \cdot k_{\mathrm{OH}} C_{\mathrm{PAH}}} .
$$

The obtained results are collected in the last column of Table 1 . The level of hydroxyl radical concentrations are in accordance with literature data $[11,20]$ and vary in the range $10^{-15}$ to $10^{-12} \mathrm{M}$.

Concerning the applicability of ozonolysis enhanced by UV radiation in PAHs degradation process it is worth to compare this AOP with a separately occurring ozonolysis [25] and photolysis [6]. Figure 7 presents the conversion of studied PAHs depending on the applied oxidation method. For all PAHs the $\mathrm{O}_{3} / \mathrm{UV}$ system is the most effective process of their removal from water. BAP is decomposed by photolysis with close efficiency; CHR little worse by ozonolysis and FLU more or less equally by ozonolysis and photolysis. Comparing the photolysis and ozonolysis of selected set of PAHs, representative for condensed aromatics, it is seen that the efficiency of the used degradation method depends on the structure of a target compound. For this reason the application of $\mathrm{O}_{3} / \mathrm{UV}$ system is advisable for natural water purification, as it usually contains a mixture of PAHs of various structures.

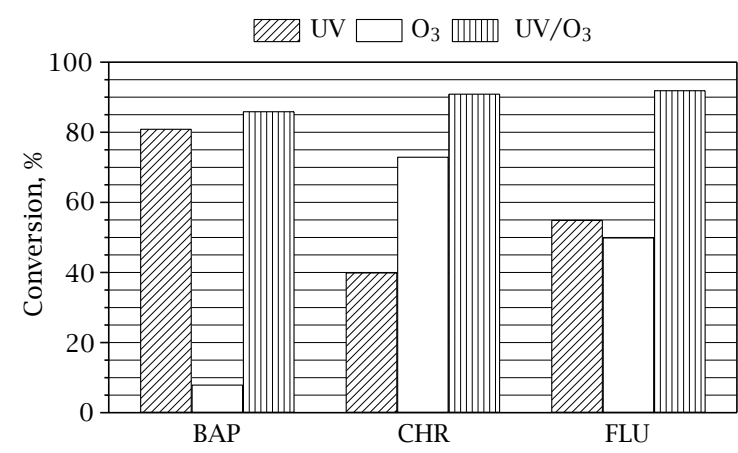

Figure 7. Comparison of three methods of PAHs degradation, for BAP and CHR after $75 \mathrm{~s}$; for FLU after $600 \mathrm{~s}$ of reaction. Conditions as in Figure 4.

\section{CONCLUSIONS}

The experiments performed on BAP, CHR and FLU elimination from aqueous solution using $\mathrm{O}_{3} / \mathrm{UV}$ system allow us to draw the following conclusions.

The ozonation combined with UV radiation is an effective and quick method for selected PAHs removal from the aqueous environment. The highest rate of degradation is achieved in acidic solutions and the slowest in alkaline solutions. The process carried out in the presence of hydroxyl radical scavenger suggests that $\mathrm{BAP}$ and $\mathrm{CHR}$ decomposition follows the radical reaction to some extent, but for FLU it is not so obvious. The behaviour of FLU in the degradation processes using UV radiation [6] ozone [25] and $\mathrm{H}_{2} \mathrm{O}_{2} / \mathrm{UV}$ [20] system is also different than that of BAP and CHR. Especially, the influence of $\mathrm{pH}$ and hydroxyl radical scavenger on the reaction course is distinct, which could indicate a more complicated mechanism of its decomposition.

The simple kinetic model, experimental and literature data [6] enable computation of the rate constants of direct ozone reaction with PAHs. The obtained values equal to $6.8 \times 10^{4}, 6.9 \times 10^{3}$ and $62 \mathrm{M}^{-1} \mathrm{~s}^{-1}$ for BAP, CHR and FLU, respectively.

The oxidation of PAHs in the $\mathrm{O}_{3} / \mathrm{UV}$ system can develop according to the three types of mechanisms. The dominating pathway of degradation depends on the structure of individual PAH. In neutral solution BAP is mainly oxidised by direct photolysis, CHR undergoes reaction with hydroxyl radical and FLU disappears first of all by direct ozonolysis.

The comparison of the three methods of PAHs degradation using $\mathrm{O}_{3}$, UV radiation and $\mathrm{O}_{3} / \mathrm{UV}$ system permits us to state that the combined process is the most effective. The application of this system instead of ozonation or photolysis is advisable for natural waters containing the mixture of various PAHs.

\section{NOMENCLATURE}

$a$ - specific interfacial area

$C$ - concentration

$F$ - fraction of absorbed radiation

$I$ - intensity of UV radiation

$I_{\mathrm{a}}$ - intensity of absorbed UV radiation

$k$ - rate constant

$k_{\mathrm{L}}$ - liquid phase volumetric mass transfer coefficient

$Q_{\mathrm{v}}$ - volumetric flow rate

$r$ - reaction rate

$t$ - time

$Y_{W}$ - ozone content in feeding gas

\section{Greek letters}

$\gamma$ - contribution of particular reaction in the process $\varphi$ - quantum yield

\section{Subscripts}

BAP - benzo[a]pyrene

CHR - chrysene

FLU - fluorene

$\mathrm{O}_{3}$ - ozone

$\mathrm{OH}$ - hydroxide radical

PAH - polycyclic aromatic hydrocarbon

UV - ultraviolet radiation

\section{Superscript}

$o$ - initial value 


\section{ACKNOWLEDGEMENTS}

The authors are grateful to the State Committee for Scientific Research (Poland) for a financial support through grant no. 3T09C02412.

\section{References}

[1] R. Criegee, Methoden der Organischen Chemie, E. Müller (ed.), 4th edition, Georg Thieme Verlag, Stuttgart, 1952.

[2] P. S. Bailey, J. E. Batterbee, and A. G. Lane, J. Am. Chem. Soc. 90 (1968), 1027.

[3] J. Hoigne, Chemistry of Aqueous Ozone and Transformation of Pollutants by Ozonation and Advanced Oxidation Processes, in The Handbook of Environmental Chemistry, J. Hrubec (ed.), Springer-Verlag, Berlin, Heidelberg, 1998.

[4] Lehto, E. Vourimaa, and H. Lemmetyinen, J. Photochem. Photobiol. A 136 (2000), 53.

[5] W. S. Schutt, K. Feng, K. S. Bousman, N. Gao, and Y. Li, J. Adv. Oxid. Technol. 2 (1997), 401.

[6] J. S. Miller and D. Olejnik, Wat. Res. 35 (2001), 233.

[7] O. Legrini, E. Oliveros, and A. Braun, Chem. Rev. 93 (1993), 671.

[8] M. Prados, H. Paillard, and P. Roche, Ozone Sci. Eng. 17 (1995), 183.

[9] M. Trapido, Y. Veressenina, and R. Munter, Ozone Sci. Eng. 16 (1994), 475.

[10] M. Hautaniemi, J. Kallas, R. Munter, M. Trapido, and Y. Veressenina, Lappeenranta University of Tech- nology, Vol. 82, Finland, 1997, p. 1.

[11] F. J. Beltran, G. Ovejero, J. F. Garcia-Araya, and J. Rivas, Ind. Eng. Chem. Res. 34 (1995), 1607.

[12] W. Bakowski and D. Bodzek, Archiwum Ochrony Środowiska (in Polish) 197 (1998), 3.

[13] M. Maier, D. Maier, and B. J. Lloyd, Wat. Res. 34 (2000), 773.

[14] S. L. Murov, I. Carmichael, and G. L. Hug, Handbook of Photochemistry, 2nd edition, Marcel Dekker, 1993.

[15] P. Głuszcz and H. Michalski, Inżynieria i Aparatura Chemiczna (in Polish) 1 (1989), 15.

[16] F. J. Beltran, Ozone Sci. Eng. 21 (1999), 207.

[17] J. S. Miller, Anal. Chim. Acta 388 (1999), 27.

[18] H. Bader and J. Hoigne, Wat. Res. 15 (1981), 449

[19] Y. Ku, W.-J. Su, and Y.-S. Shen, Ind. Eng. Chem. Res. 35 (1996), 3369.

[20] S. Ledakowicz, J. S. Miller, and D. Olejnik, International Journal of Photoenergy 1 (1999), 55.

[21] M. S. Elovitz and U. Von Gunten, Ozone Sci. Eng. 21 (1999), 239.

[22] I. Nicole, J. De Laat, M. Dore, J. Duguet, and C. Bonnel, Wat. Res. 24 (1990), 157.

[23] G. V. Buxton, C. L. Greenstock, W. P. Helman, and A. B. Ross, J. Phys. Chem. Ref. Data 17 (1988), 513.

[24] M. Trapido, Y. Veressenina, and R. Munter, Environ. Tech. 16 (1995), 729.

[25] J. S. Miller and D. Olejnik, Ozonation of PAHs in Water Solution, 15th Congress of the International Ozone Association, London, England, 2001. 


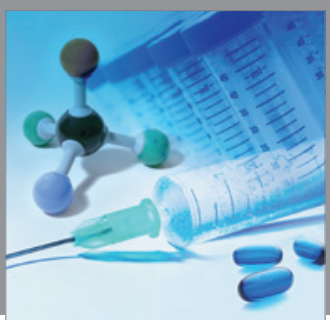

International Journal of

Medicinal Chemistry

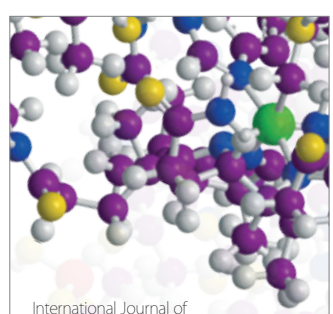

Carbohydrate Chemistry

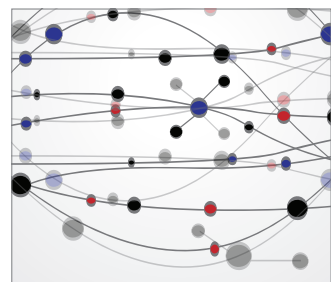

The Scientific World Journal
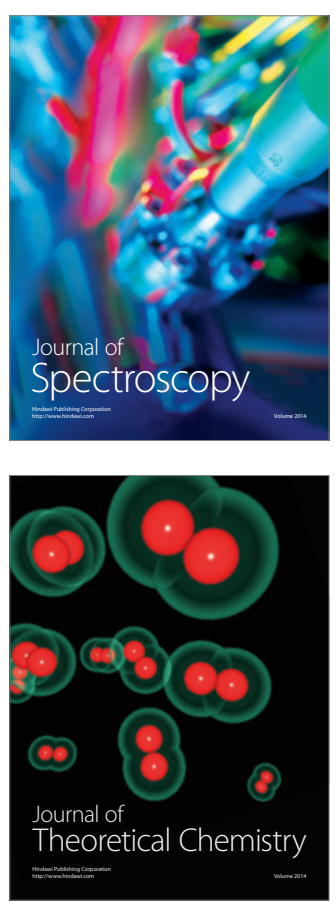
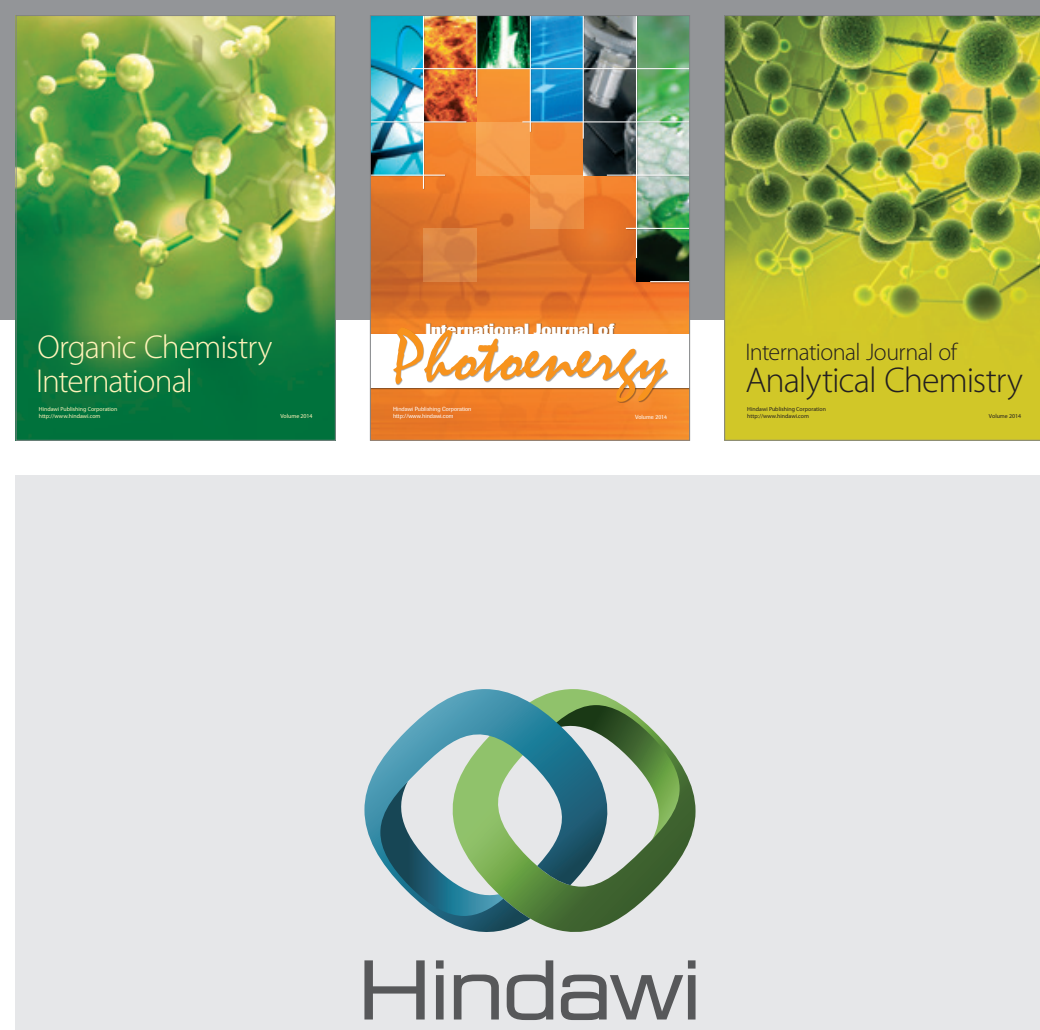

Submit your manuscripts at

http://www.hindawi.com
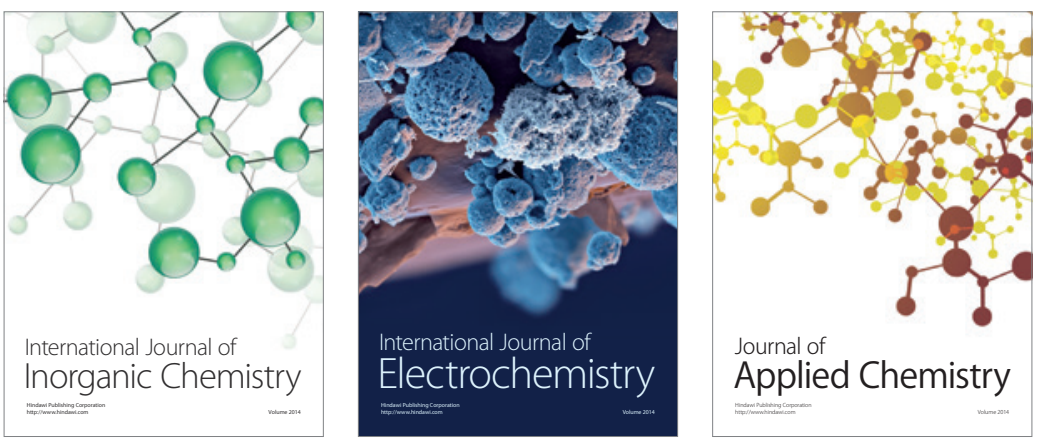

Journal of

Applied Chemistry
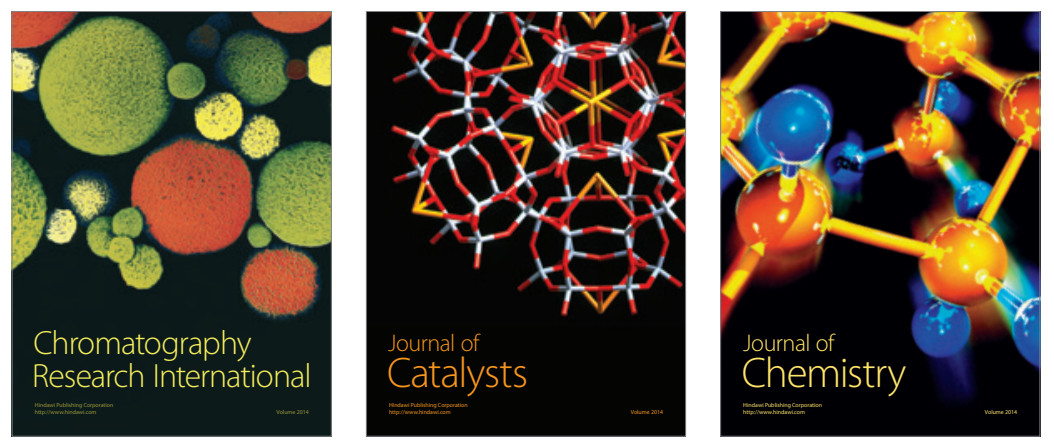
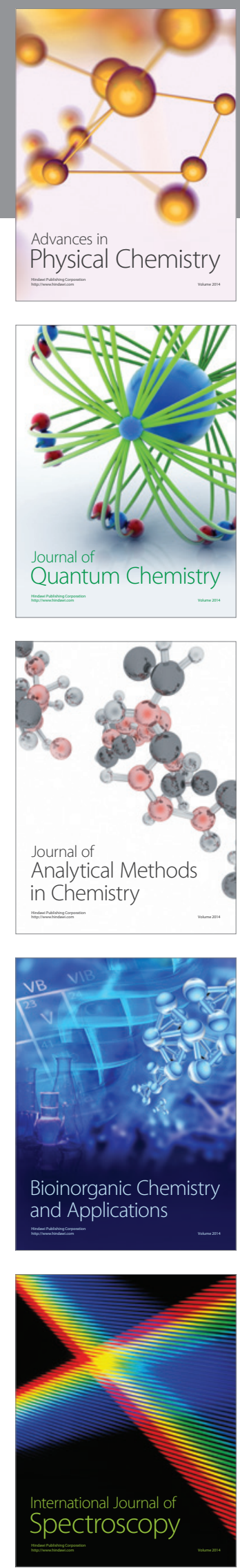